\title{
APE 2018 Selected Reports
}

\author{
Anthony Watkinson* \\ Research England, Nicholson House, Lime Kiln Close, Stoke Gifford, Bristol, BS34 8SR, UK
}

Academic Publishing in Europe 2018 was in its thirteenth year. APE is the brainchild of Arnoud de Kemp and Einar Fredriksson. From the beginning the Conference venue has been the Leibniz Hall of the Berlin-Brandenburg Academy of Sciences and Humanities at Gendarmenmarkt in Berlin. It brings together academic publishers and librarians, researchers and suppliers in a European context. The presentations reported on were selected by Mr. de Kemp as substantial contributions of interest to the wider Information community. The complete programme for the conference and videos of the presentations can be found at https://www.ape2018.eu/.

\section{David Sweeney, Executive Chair of Research England}

\section{The UK, Europe and Scholarly Publishing, Authors, Employers and Publishing}

David Sweeney took up his present post during 2018. He is a statistician by training, has worked in university education and since 2008 has been in government.

In his opening remarks he explains that dialogue is important and that government and funders will supervise plans for the future with input from industry and consumers. The Finch process [1] in the UK, which he set up, was based on the idea of partnership and a commitment to Open Access. The financials were to be worked out.

How has it gone? Should we have started with confrontation? He quoted from Danny Kingsley [2] whose view is that it did not work.

UK is an outlier in supporting gold OA and has achieved good results in OA articles (37\%) and hybrid has helped but is perceived a unfair and perception is important. Kingsley points out that $80 \%$ of her APC budget goes on articles in hybrid. But they have not managed to flip journals from subscription to OA.

Kingsley asks - how can we get out of this mess? Her views are worth thinking about.

Sweeney quoted Adam Tickell's UUK report [3] which is generally positive about Finch - for balance. These are contrasting views. He refers to the thinking of the United Kingdom Research Initiative (UKRI) which is taking the objectives forward.

Talk about grotesque profit margins may be a consumer view but it is not a helpful comment. Academics can decide where they publish and they submit where they think they will get most value. Funders subsidise but cannot support in the longer term a market which does not work. Price cannot be attached

\footnotetext{
*E-mail: anthony.watkinson@btinternet.com.
} 
directly to value. Is such a market even possible where consumers do not decide on price - there needs some level of disruption?

The National Scholarly Communications Licence [4] will however bring together universities and academics. He is not happy about industry attitudes and worries that the partnership is under threat. DORA [5] is about value and is therefore important but he does agree that there is some correlation and price which has to be admitted. Are universities actually implementing DORA even when they sign?

This is their analysis and they are wondering whether they can continue to partner with the industry. The Industry have to deal with hybrid. This is a steer but he does not have a view overall.

In the questions Bernd Pulverer from EMBO Journal pointed out that assessment is not rewarded but instead represents a cost: can his organisation help? Sweeney does not think you can divide up the money available in this way.

Pulverer had a second question. Can we really not work out costs? The answer was that learned societies often subsidise other mission driven functions. Commercial publishers cannot disclose costs and he does not blame them.

The chair was surprised by some of Sweeney's statistics. Sweeney can only guess why highly rated journals are more costly. There are opposing views.

Bob Campbell, formerly of Wiley-Blackwell, asked, whether if Finch does not work can there be a new vehicle? Sweeney was not sure the partnership, which is the essence of Finch, has (yet) broken down. As this report goes to press does the 4 September declaration from Science Europe, to which the UK Research and Innovation (UKRI) is a signatory, mean that the decision has been made and a confrontational position has been decided upon [7].

\section{Jean- Claude Burgelman, Head of Unit: Open Data Policy and Science Cloud, Directorate A - Policy Development and Coordination, DG RTD, European Commission, Brussels}

\section{The EU Open Access Policies - from Vision to Action}

The speaker has been 14 years at the European Commission jointly with 31 years as a full professor of communication technology policy at the Free University of Brussels.

It is important to remember that this report is being written almost eight months after the presentation was delivered and some of what is discussed as in the future should be happening now or have happened. Professor Burgelman pointed to https://ec.europa.eu/research/openscience for further and future (current) information.

Six years ago he spoke about the future and need for disruption and now 'Publishing 2020 Ramping up Relevance' is advanced.

Not just open access or open science but more than that impacts on the whole ecosystem of science and the support for innovation which is so important as a result of scientific advance. There has been lots of support from the Commission especially from 2012. The Dutch and Germans have been particularly active.

There has also been a lot of consultation leading up to a report in 2015. It is bottom-up and co-designed. He wants to insist on this. Agenda is eight topics with 2020 or earlier deadline including open data, altmetrics (new generation metrics), open science cloud and the future of scholarly communication (all peer reviewed). The softer side where there is subsidiarity is involved (where national decision making is central) and that includes rewards (incentives), research integrity, education and skills, and citizen science. 
To give one example you should be able to make a scientific career and never publish an article because your reputation will be based on data.

He gave examples of progress such as the 'Open Access Publications Platform' (2018), the fact that open access to data will be mainstreamed in all states in this year also, and the Open Science Cloud is launched in 2018 in first phase. He would like to come back in 2019 to tell us how successful it has been.

The political context for OA has completely changed in six years and there is general national support. The business context has changed and there are now sustainable OA models for publishers.

There is also the launch of their own platform which is much like the Wellcome. It is complementary and not compulsory and is offered to researchers who can find nowhere to go. They will be looking to novel ways of peer review, new metrics will be tested out and also there will be preprint support. It must aim for the highest quality. It will be a sort of mega-journal. There is a budget of E6.4 million which is expandable.

The Cloud is a cross disciplinary space to enable open data to be used across different areas. This is what the environment is all about. Need for interoperability. At this stage there were 110 participants signed up. Compliance is encouraged by incentives and rewards and FAIR principles are enforced. We have to be in the lead of the mining too.

As already mentioned FP9 (the new Framework Programme) goes beyond publications and data to embrace and incentives Open Science as modus operandi - it is in planning (https:/ec.europa.eu/ programmes/horizon2020/en/tags/fp90).

There is just time for this snapshot: Open is here to stay which could not have said six years ago. We are just at the beginning however and he provided some aims. The Chan Zuckerberg Foundation pledges to eradicate all disease. This is a Grand Challenge!

The EC are looking for as their downstream aims

- User centred Publishing delivering Precision information,

- the Machine as the New reader,

- Science as a Social Machine,

- Data privacy requires a web of trust,

- Big data meets artificial intelligence

Scientific publishers will become open science platforms in which the article is one of many products. He sees this as disruptive. We tend to underplay this in Europe and therefore the big players in the Internet are not found here. We can win this time.

\section{David Neal, Senior Vice President for Global Research Elsevier and Professor of Surgical Oncology, Nuffield Department of Surgical Sciences, Oxford University}

\section{How can Academic Publishers help the Academic Clinician?}

Professor Neal was trained at University College London, Leeds and Newcastle and, between 2002 and 2014, he held the Foundation Chair of Surgical Oncology in the University of Cambridge. In 2014 took up his current two roles. He has published over 490 peer reviewed papers.

His career has been disrupted three times as new surgical procedures result in wholesale changes in modes of operating - so he knows about disrupting! 
The business of academic publishing is still controversial but it has a future if it listens He joined Elsevier because he was passionate about knowledge based treatment as part of making the world a better place.

How can this be done especially in view of the huge increase of academic papers? R \& D continues to increase and particular importance is the role of China. No one individual can keep up with their specialisation. Publishers have a crucial role here. They have added a huge value and have taken a leading role in integrity, transparency and quality. They do however have to work in partnership with the academic community.

Young scientists are keen on their career and they know how the tenure track works in spite of what other speakers have said. He has practical knowledge of this. The journal brand remains important as we can see: for example, the score in the REF can be correlated with the impact factors of journals where papers are published.

From his point of view as a clinical academic what can publishers do?

There is a need for tools based on natural language processing and using artificial intelligence.

The industry needs to be on top of health care informatics to serve clinicians properly.

There is a growing provision of analytics among publishers which in some fields have big impacts. These analytics have to be tailored. They have to be embedded. Busy people do not like to move from the site they are used to. The analytics have to be user driven not content driven.

One important task is the Improvement of reproducibility in publications which is of central importance in medicine and there are huge implications on precision medicine and on the work of the pharmaceutical industry. It is not necessarily an issue of research integrity.

Researchers worry about publishing but also about reviewing. Researchers worry about how to present their data - putting datasets together so that they can be really useful.

In general there will always be a need for validation and he cannot buy into the idea of just putting information out there as some have proposed. He has also outlined a few ways in which publishers should adapt.

There are global challenges to health care systems and these are not the elderly only but other high cost populations. He showed graphs on health and social care which demonstrates that France spends $35 \%$ of GDP on both, a contribution which cannot be sustained. US is highest on health spending but the spending on social care is low. Publishers can help prevent such costs from increasing by stepping up their game. There are preventable errors in medicine.

Important issues:

- deep understanding needed as a basis for health care informatics

- improving reproducibility has already been mentioned

- Data sets may be open but there are usually errors and you have to go back to originators

- Decision support helped by image analytics

To summarise:

Publishers do have a great future in ways described.

From the floor David Sweeney, who had spoken earlier, does accept the value in analytics but he does not see how it has to work with primary publishing and indeed there could be a conflict with open publishing. Is Professor Neal not describing something which is new - a new role not necessarily one for traditional publishers? Neal considered what he proposes coming naturally from the existing work of a publisher. Publishers will have to work together in the synthesis of new knowledge. Their core business is still providing trusted knowledge and building on it. 


\section{Nicko Goncharoff, Chief Business Development Officer, Digital Science, London}

\section{Open Science - How can publishers best provide value amidst changing user expectations?}

He is launching a product this week so he has to talk about this but not too much. It is 'Dimensions' - here is the site (https://www.digital-science.com/products/dimensions/) and here is the strapline: Dimensions is a next-generation linked research information system that makes it easier to find and access the most relevant information, analyse the academic and broader outcomes of research, and gather insights to inform future strategy.

Publishers are not missing the boat and they have adapted to open science and data. The boat is a kayak not a speedboat and has navigated some early rapids and yes it does need a bigger boat.

OK publishers are still dependent on subscriptions which may not be a bad thing. Article sharing is not so worrying to publishers as it was in five years ago. There are various partnerships, often initiated by STM, which include the STM Voluntary Principles on Article Sharing, the STM Tapas project. RA 21, ORCID, Metadata 2020, Open Citations Initiative, Crossref and others and there has been a lot of time and money spent on this. And of course individual publishers have made their own contributions.

Discovery, relevancy, awareness and ease of access are more important than a free ride so instead if demanding that everything must be free we should aim for accessible and affordable (which may include free) Some talks have made the relevance of this as an aim clear earlier in the meeting.

What does Accessible look like? It includes making clear whether an article or book can be seen quickly to be useful or not. And it is important that you do not need to jump through hoops to get there.

Metadata is very important and has to be incorporated.by publishers. Goncharoff knows metadata is boring but he does not apologise. He supports Metadata 2020.

It is crucial that researchers can legitimately access content which means bringing toward uniform recognition and granting of access rights. This is part of RA21 which he also thoroughly supports.

How does free or affordable happen?

Of course flip to OA or launch as OA as many journals as possible but for those that are not sustainable as $\mathrm{OA}$ include as many options as possible:

- Sharing initiatives to at least gauge relevance

- Rental or other lower cost purchase options

- Streaming models

- Working with institutions and vendors on alternatives to interlibrary loan

What can publishers do to support open data:

- Support and advocate for common data/metadata standards

- Actively work with other stakeholders to provide common data policies. Scholix is an excellent example

- Support better metadata curation via submissions and editorial processes

- Make supplementary data linked and thus discoverable. Add unique identifiers to all datasets

How would this serve the research community?

It will make all sorts of stakeholders including the funders and the general public reach what they need. They may not all need the original research papers. The more metadata is out there the better their new tool Dimensions will be. They have generated 4 billion links between research objects which explains relevance and relationships. 
How do publishers benefit? There will be more traffic and revenue and indeed authors. You are less dependent on Google and you are aligned to missions of funders. There are internal gains if your systems work together. It has already begun but there is more work to be done.

\section{Building an Academic-Led Publisher for the Digital Age}

Dr Caroline Edwards, Senior Lecturer in Modern \& Contemporary Literature at Birkbeck, University of London and Editorial Director of the Open Library of the Humanities, London, UK.

Caroline Edwards has been a university teacher since 2008 with a distinguished list of publications but it is her work with Martin Eve on the OLH since its foundation in 2015 which was the subject of her presentation.

She gave a whistle stop view of a different take on journals as both an academic publisher and practicing academic in the humanities. It was clear to her that her picture is going to challenge some of the assumptions offered so far which assume that sciences are the norm. Humanities get neglected and yet they have a special kind of approach to research which means that the way submissions are reviewed diverges from the scientific model.

Academics are not just consumers. They are not just giving value-added tasks for free but they are producing the content themselves. The case of making scholarship available is gaining strength and mandates are being established at a national level. Now concerned with the logistics not whether it will happen.

She includes publishers as stakeholders and we have to work together with other stakeholders. There are born-digital publishers and include the Open Humanities Press by-passing other publishers and existing for some years. Technology itself may be a disruptor but it is harnessed by people.

The OLH launch had a social side as well as a technology side. How are current editorial practices being affected for example new types of peer review? OLH is in favour of open peer review but most academics in their disciplines especially younger ones do not feel secure with too much openness. Past questioning of the quality of open access publications intrinsic to the business model is now irrelevant as indeed it is in science. Their publications sit within a larger research process - disaggregating one product (hermetically sealed) and instead being concerned with the whole work flow. They see themselves as in the space as humanities commons and the MLA commons both platforms which are part of scholarly networks and are in part a non-profit alternative to the for-profit social collaboration network Academia - by far the largest in these disciplines. There are other innovators too. The Media Commons Press is mentioned but not (surprisingly) the rather bigger Knowledge Unlatched which maybe because it has only very recently taken on boar journals as well as books.

As far as preprints are concerned she is impressed by recent new preprint platforms but she is not yet sure about its utility in the humanities - sharing before ready is not art of the culture. What are the multimodal possibilities of online-only publishing? It includes annotations. There are exciting opportunities for getting away from fixed articles, especially if constantly updated using open sources.

In her field of literary studies research can be engaged with visual-based film studies - embedding clips of videos which they allow for though there are challenges. She herself edits a megajournal and sees future opportunities here especially for multi-disciplinary articles.

What are the barriers? It remains true that venue of publication is important but the editor of the journal does also count and they aim for editors who encourage quality. The reliance of most publishing models on APCs have led to transferring the cost of publishing from reader to author - but this not work in the 
humanities where there is little money available and many do not have permanent posts. It is an unfair system and militates against younger scholars in favour of established ones. Prices over \$2000 per article are impossible in her disciplines for most people. She used information from JISC Collections [8]. There is a limit to what libraries can afford to pay and it is preventing even greater increases.

Are there alternatives? This is where the OLH comes in and it is was one of the reasons why Martin Eve and she started it in 2015. APCs have no future in the humanities. OLH is funded by an international consortium of libraries. They do have a big multi-disciplinary journal (initially their aim) but soon became a platform for lots of journals. Their model is the Library Partnership Subsidy. It is mission-based a mission which they as a publisher share with libraries. 230 libraries have signed up at the beginning of the year and are aiming to reach 300 at the end (2018). It includes all Irish Universities. The libraries feed into decisions on starting or taking on new journals.

They actually know how much it cost because they directly organise production etc. They use HTML typesetting. This is as well as PDF - rare in the humanities. The do all the things you would expect from a larger company including making sure that the journal is indexed and that DOIs are applied to each article. Their journals are archived and preserved in CLOKSS. Edwards did not mention another initiative of OLH (presumably because it was then still under warapps). This is an open source publishing platform (Janeway) created at her university (Birkbeck) to support the OLH goals [9].

OLH currently publishes 23 (now 24) journals. They could have published more but they want to maintain their quality level and also their level of efficiency. Many of the journals that are offered to them are rejected. They have a range of different disciplines. Many of their journals still use issues as if they were printed in spite of rolling publication (article by article) which is routinely offered.

In the UK academies are told that the REF does not take into account place of publishing but this is not accepted by British academics yet. Academics are wedded to existing journals and there is a lot of conservatism endemic in their disciplines. They are keen to publish or fund existing journal preferably learned society journals [10]. This is why they offer to publish journals when contracts come up for renewal.. There is a lot of interest. Many academics running journals are unhappy with publishers who not let them have hybrid OA and who have other complains about the service available from their publishing partners.

Jill Taylor-Roe from the floor asked in what other ways libraries can help. Edwards says that Lyrasis and JISC Collections are working with them. It needs action by library directors to set aside part of their budget. At present more support is needed and they are working on new support strategies to see if there are ways of tweaking their current one. It is not yet clear that the OLH approach scalable?

A learned society questioner was worried about loss of the journal in the post and also loss of Membership/ revenue. Giving up print does not seem to worry those three learned societies they currently work with.

\section{References}

[1] The Working Group on Expanding Access to Published Research Findings 2018, http://ukrio.org/open-access-researchreport-of-the-finch-group/.

[2] https://www.universitiesuk.ac.uk/policy-and-analysis/research-policy/open-science/Pages/uuk-open-access-coordinationgroup.aspx.

[3] Danny Kingsley, So did it work? Considering the Impact of Finch 5 years on. Presentation 2017, https://www.repository.cam.ac.uk/bitstream/handle/1810/269913/PRE_LondonInfoInternat_V3_20171205.pdf? sequence $=4 \&$ isAllowed $=\mathrm{y}$. 
[4] (Tickell, Adam) Monitoring the transition to open access. Report 2017, https://www.universitiesuk.ac.uk/policy-andanalysis/reports/Pages/monitoring-transition-open-access-2017.aspx.

[5] UK Scholarly Communications Licence and Model Policy retrieved at 4th September 2018, http://ukscl.ac.uk/.

[6] San Francisco Declaration on Research Assessment 2012, https://sfdora.org/.

[7] Plan S - Accelerating the transition to full and immediate Open Access to scientific publications. Science Europe 2018, https://www.scienceeurope.org/wp-content/uploads/2018/09/Plan_S.pdf.

[8] https://scholarlycommunications.jiscinvolve.org/wp/2017/08/23/article-processing-charges-in-2016/.

[9] Martin Paul Eve and Andy Byers, Janeway: A Scholarly Communications Platform, UKSG Insights 31(15) (2018), 1-4. doi:https://doi.org/10.1629/uksg.396.

[10] https://www.openlibhums.org/site/academics/journal-applications-to-join-the-olh/. 